\title{
A usabilidade e acessibilidade de um ambiente virtual de aprendizagem com foco no usuário idoso: uma verificação ergonômica do Moodle
}

\section{Usability and accessibility of a virtual learning environment centered on elderly users: an ergonomic check on Moodle}

\author{
Josiane Vieira Campos ${ }^{1}$, Thaiana Pereira dos Anjos ${ }^{1}$, Leila Amaral Gontijo ${ }^{1}$, Milton Luiz Horn Vieira ${ }^{1}$ \\ ${ }^{1}$ Universidade Federal de Santa Catarina - UFSC, Brasil
}

Autor para correspondência/Mail to: Josiane Vieira Campos josiane.campos@posgrad.ufsc.br

Financiamento/Funding: $\mathrm{CNPq}$

Recebido/Submitted: 10 Jun. 2015; Aceito/Approved: 01 Ago. 2015

Copyright (c) 2015 Campos et al.. Todo o conteúdo da Revista (incluindo-se instruções, política editorial e modelos) está sob uma licença Creative Commons Atribuição-NãoComercial-Compartilhalgual 3.0 Não Adaptada. Ao serem publicados por esta Revista, os artigos são de livre uso em ambientes educacionais, de pesquisa e não comerciais, com atribuição de autoria obrigatória. Mais informações em http://ojs.c3sl.ufpr.br/ojs2/index.php/atoz/about/submissions\#copyrightNotice.

\begin{abstract}
Resumo
Introdução: o público idoso tem, em geral, características físicas, fisiológicas e cognitivas que dificultam a interação com produtos e sistemas eletrônicos e digitais, particularmente aqueles disponíveis em ambientes virtuais. Visto que a educação à distância tem se expandido consideravelmente, atingido os mais diferentes públicos e regiões, este artigo objetiva identificar recomendações de usabilidade e acessibilidade, para este público-alvo, no Moodle do Instituto Federal de Educação, Ciência e Tecnologia de Santa Catarina (IFSC).

Método: a investigação consistiu em quatro etapas: 1) pesquisa na literatura de recomendações de usabilidade e acessibilidade; 2) avaliação heurística do Moodle do IFSC; 3) identificação de características e consequências do envelhecimento que influenciam na utilização do Moodle pelo público idoso; e, 4) recomendações de usabilidade e acessibilidade para o Moodle com foco no usuário idoso.

Resultados: as recomendações estão relacionadas com as funcionalidades, as os problemas de usabilidade e acessibilidade detectados na avaliação heurística e as características e consequências do envelhecimento.

Conclusão: as recomendações de usabilidade e acessibilidade propostas podem auxiliar na inclusão digital do idoso, facilitando o seu aprendizado e o uso do ambiente, fomentando assim, a efetividade do processo educacional à distância e a possibilidade de uso do sistema pelo público idoso.
\end{abstract}

Palavras-chave: Usabilidade; Acessibilidade; Ambiente Virtual de Aprendizagem (AVA); Educação inclusiva; Idosos; Instituto Federal de Educação, Ciência e Tecnologia de Santa Catarina (IFSC)

\begin{abstract}
Introduction: the elderly population has, in general, physical, physiological and cognitive characteristics that hinder interaction with products and electronic/digital systems, particularly those available in virtual environments. Since distance education and learning has expanded considerably, reaching the most different audiences and regions, this article aims to identify recommendations of usability and accessibility for the elderly users at the AVA/Moodle of Federal Institute of Education, Science and Technology of Santa Catarina (IFSC).

Method: the research consisted of four steps: 1) literature search about recommendations for usability and accessibility; 2) heuristic evaluation of the IFSC Moodle; 3) identification of characteristics and consequences of aging that could influence the use of Moodle for the elderly population; and, 4) discussion of usability and accessibility recommendations for the ISFC/Moodle centered on the elderly user.

Results: The recommendations are related to the features and the problems of usability and accessibility detected in the heuristic evaluation and the characteristics and consequences of aging.

Conclusion: the usability and accessibility proposals may assist in the digital inclusion of the elderly, assisting their learning and use of the environment, thereby promoting the effectiveness of a distance education as well as widening the use of the system by the elderly public.
\end{abstract}

Keywords: Usability; Accessibility; Virtual Learning Environment; Elderly; Instituto Federal de Educação, Ciência e Tecnologia de Santa Catarina (IFSC)

\section{INTRODUÇÃO}

O idoso era caracterizado pela sociedade, há bem pouco tempo atrás, como um ser com expectativa de vida curta e sem saúde (Anjos, 2012). Porém, em decorrência dos avanços da Medicina e de uma decorrente melhor qualidade de vida, esta caracterização se alterou e, atualmente a "idade avançada não indica o fim da vida de uma pessoa, mas apenas a intensidade das atividades do dia a dia que diminuem” (Anjos, 2012, p. 35).

A expectativa de vida da população aumenta a cada ano e, consequentemente, a população de idosos se mostra em crescimento. Para o Instituto Brasileiro de Geografia e Estatística (IBGE) uma pessoa é considerada idosa quando tem uma idade igual ou superior a 60 anos (Instituto Brasileiro de Geografia e Estatística [IBGE], 2010). O crescimento do número de idosos progrediu de 3,3 milhões em 1960, representando 4,7 porcento da população, para 14,5 milhões - ou 8,5 porcento dos brasileiros - em 2000, sendo que em 2010 a representação da população idosa passou para 20,5 milhões (10,8 porcento do total) (Instituto Brasileiro de Geografia e Estatística [IBGE], 1960, 2000, 2010). 

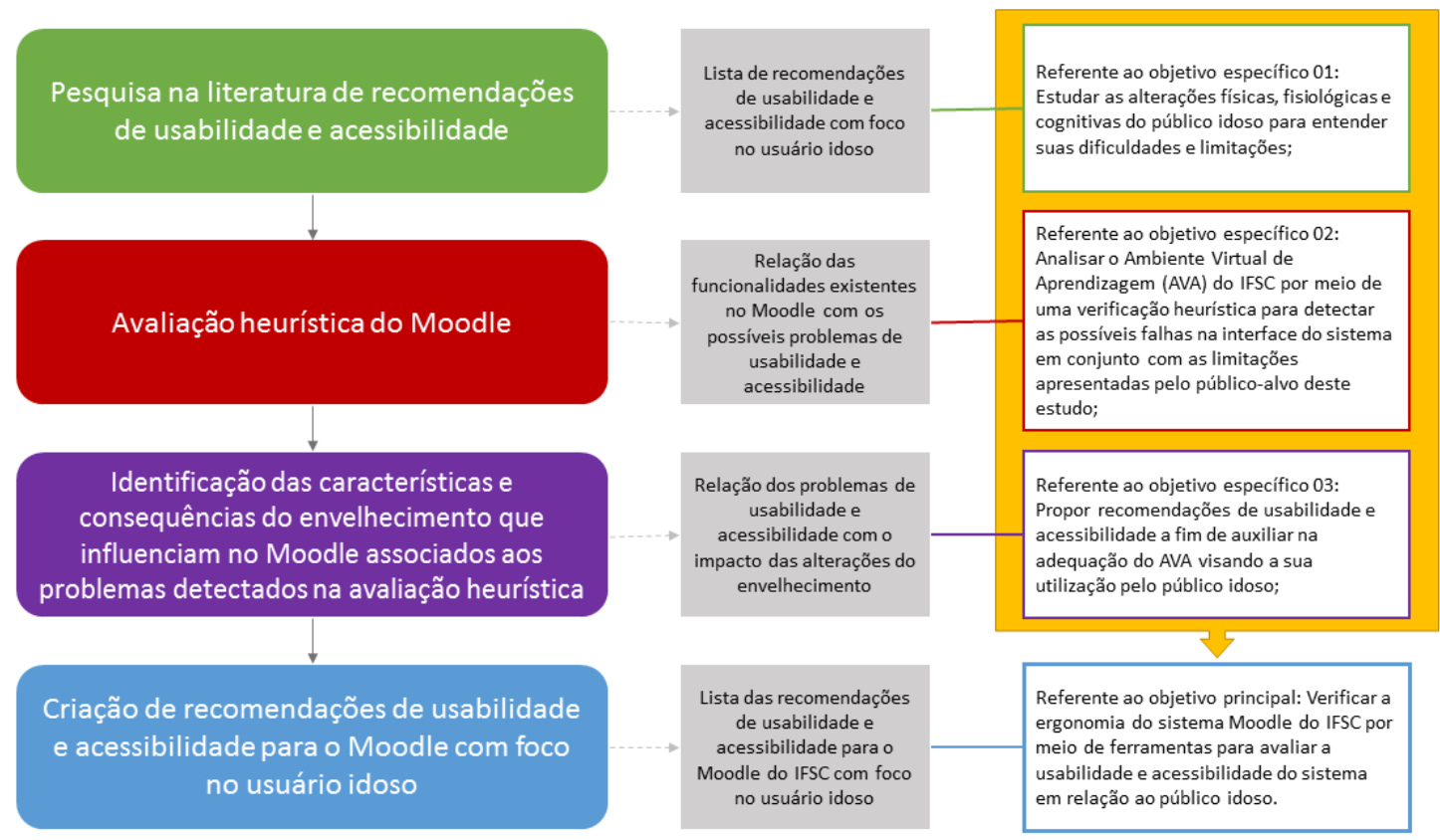

Figura 1. Etapas metodológicas e resultados de cada etapa.

Fonte: os autores (2015).

Ligado ao crescimento da população idosa, o ensino à distância (EAD) apresenta uma evolução, principalmente no Instituto Federal de Educação, Ciência e Tecnologia de Santa Catarina (IFSC). Neste, novos cursos entraram em vigor a partir do ano de 2010, possibilitando a profissionalização diferentes tipos sociais em diversos tipos de cursos e nas regiões distantes de grandes centros, proporcionando uma mudança no quadro econômico e social do País. A tecnologia aplicada ao ensino à distância estimula este avanço no território brasileiro, e promove uma constante evolução nas possibilidades de acompanhamento individual no ensino.

Os ambientes virtuais estão inseridos no processo interativo e educacional necessário na EAD. Porém, estes ambientes muitas vezes não estão planejados para a utilização por públicos diversificados, contemplando usuários de diferentes faixas etárias e nichos intelectuais, o que tende a excluir inúmeras pessoas e pesar como um fator negativo para tais sistemas. Os usuários idosos, por não serem nativos digitais, não possuem total familiaridade com tal tecnologia, e realizar funções básicas no Moodle, tais como acessar o sistema ou enviar um arquivo, pode se tornar uma tarefa desmotivadora. Além disso, de acordo com Aumüller, Aust, e Wurzinger (2009) o processo de envelhecimento acarreta em alterações fisiológicas capazes de influenciar as aptidões visuais, perceptivas e cognitivas do indivíduo. Além disso, Souza e Rossini (2011) afirmam, nesta etapa de vida, a velocidade de processamento das informações, precisão e resposta aos estímulos é reduzida.

Diante destes fatos, esta pesquisa analisa, de forma geral, quais são os possíveis desafios que o idoso encontra ao interagir com a interface de um ambiente virtual de aprendizagem e quais são os parâmetros para adequar este tipo de sistema a fim de minimizar ou extinguir os problemas enfrentados pelos idosos na interação com esse tipo de interface. Tal pesquisa se embasa em parâmetros ergonômicos de acessibilidade e usabilidade para identificar fragilidades e propor mudanças ao ambiente virtual com o intuito de fomentar a interação e o processo comunicacional.

\section{PROCEDIMENTOS METODOLÓGICOS}

Este trabalho caracteriza-se em uma pesquisa qualitativa descritiva em que se estuda um objeto com referência nas bibliografias encontradas. O trabalho consistiu em quatro etapas: 1) Pesquisa na literatura de recomendações de usabilidade e acessibilidade; 2) Avaliação heurística do Moodle; 3) Identificação de características e consequências do envelhecimento que influenciam no Moodle associados aos problemas detectados na avaliação heurística; e 4) Criação de recomendações de usabilidade e acessibilidade para o Moodle com foco no usuário idoso. As etapas e o resultado de cada uma podem ser visualizados na figura 1.

A primeira etapa consistiu na realização de pesquisas na literatura a respeito das recomendações de usabilidade e acessibilidade que atendam especificamente a interação homem-computador dos usuários idosos. Foram encontrados na literatura teses e artigos que abordam a usabilidade e a acessibilidade em diferentes ambientes. Ferreira, Vechiato, e Vidotti (2008), Macedo (2009), Sales (2007), Cybis, Betiol, e Faust (2010) e Zanchett (2006) 
tratam da avaliação de usabilidade de websites e sistemas em geral para a terceira idade. Anjos (2012) descreve recomendações de usabilidade para telefone celular com foco no usuário idoso, e Anjos, Campos, Gontijo, e Viera (2014) propõem recomendações para o uso de AVAs pelo público idoso.

A segunda etapa consistiu na avaliação heurística do sistema Moodle dos Cursos à Distância do IFSC para identificar as funcionalidades especificadas no apêndice 1 (criar e importar conteúdo, armazenar recursos, armazenar e visualizar todos os dados do aprendiz, monitorar atividades de aprendizado, e-mail, entre outros) e identificar possíveis problemas de usabilidade e acessibilidade para o usuário idoso. Para Preece (2002), e a heurística, no contexto de usabilidade, é um conjunto de princípios de usabilidade conhecidos que orientam os especialistas a avaliar a usabilidade de um sistema. Essa avaliação não necessita da interação com usuários, podendo ser realizada por especialistas em usabilidade. Na literatura podem ser encontradas algumas heurísticas, como as dez Heurísticas de Usabilidade desenvolvidas por Nielsen (1994), as oito Regras de Ouro de Schneiderman (1998); e os oito Critérios Ergonômicos de Bastein e Scapin (1993). As heurísticas analisadas foram baseadas nos documentos de acessibilidade da WCAG 2.0 e em Anjos (2012), Cybis et al. (2010) e (Pottes \& Spinillo, 2011). Para realizar a avaliação heurística, o especialista deve utilizar o sistema como se fosse um usuário típico e deve avaliar se os elementos da interface estão de acordo com as heurísticas selecionadas (Preece, 2002). Nielsen (1994) comenta que esse tipo de avaliação, quando realizada por cinco avaliadores, consegue identificar cerca de 75 porcento dos problemas de usabilidade no sistema. Porém, o autor também cita que avaliadores experientes podem coletar inúmeros problemas de usabilidade sozinhos (Nielsen, 1994).

A terceira etapa consistiu na identificação de características e consequências do envelhecimento que podem influenciar no uso dos AVAs pelos idosos e que são impactados por cada problema de usabilidade e acessibilidade detectado na avaliação heurística. Cada problema de usabilidade e acessibilidade encontrada foi relacionado com as alterações que ocorrem nos sistemas de orientação, auditivo, háptico (relativo ao tato), paladar-olfato e visual, (detalhados oportunamente).

A quarta etapa consistiu no desenvolvimento das recomendações de usabilidade e acessibilidade com o propósito de adequar o uso do ambiente por pessoas idosas, tanto alunos como tutores e professores, buscando inseri-las digitalmente e melhorar o compartilhamento de conhecimentos entre o público idoso e demais usuários do sistema. As recomendações de usabilidade e acessibilidade foram propostas relacionando as funcionalidades identificadas do AVA, as características do sistema e o resultado da avaliação heurística realizada no Moodle. As recomendações propostas podem ser utilizadas para o projeto de outros ambientes virtuais que possuem as funcionalidades apresentadas, porém pode ser necessário adaptá-las de acordo com o ambiente.

\section{OS AMBIENTES VIRTUAIS DE APRENDIZAGEM E A EDUCAÇÃO À DISTÂNCIA}

A EAD iniciou no Brasil em 1992 com a criação da Coordenadoria Nacional de Educação a Distância pelo MEC. Existem diversos programas do governo brasileiro que visam fomentar a EAD, como a rede de Escolas Técnicas (ETEC) e a Universidade Aberta do Brasil, que promovem a EAD em regiões interioranas do país. Este avanço da EAD se vale do progresso tecnológico que oportuniza a localidades remotas, sua inserção nos processos educacionais.

O EAD é uma modalidade de ensino que possibilita a construção do conhecimento de forma crítica, criativa e contextualizada quando não puder ocorrer o encontro presencial entre aluno e professor (Hack, 2011). Este ensino é planejado e intencional, onde são desenvolvidas didáticas para orientar o aluno a aprender com autonomia. A tecnologia é fundamental para esse processo e, neste contexto, surgem os ambientes virtuais de aprendizagem (AVAs) como formas de interação entre professores, tutores e alunos.

É por meio destes ambientes que aulas são ministradas e o aprendizado é monitorado por meio da promoção de discussões e realização de atividades e avaliações. Por isso, tais sistemas contam com diferentes funcionalidades, tais como o gerenciamento de recursos (permitindo a criação de repositórios, importação e exportação de conteúdo); o gerenciamento de usuários (permitindo visualizar dados dos alunos, monitorar e diagnosticar a qualidade da aprendizagem do aluno individualmente, seus acessos e tempo de conexão); o gerenciamento de cursos (permitindo criar disciplinas, adicionar materiais, links e mídias, realizar atividades); e o gerenciamento de comunicação (permitindo a criação e envio de mensagens por chat, fóruns, emails, videoconferência, painel de notícias). Um dos AVAs utilizados no Brasil é o Moodle, que, dependendo da versão utilizada, pode ser configurada para suportar diferentes funcionalidades.

\section{O Ambiente Virtual de Aprendizagem Moodle}

De acordo com Perez, Zilber, Cesar, Lex, e Medeiros Júnior (2012, p. 148) O Moodle (Modular Object-Oriented Dynamic Learning Environment /Ambiente Modular de Ensino Dinâmico Orientado ao Objeto) "é um sistema de apoio à aprendizagem, executado em ambiente virtual”. Caracteriza-se por ser um Sistema de Gestão da Aprendizagem (SGA) para gerenciamento de cursos, também conhecido como Ambiente Virtual de Aprendizagem (AVA). Funciona baseado em ferramentas web, requerendo do usuário um computador conectado à 
internet. Tornou-se muito popular entre educadores de todo o mundo como uma ferramenta dinâmica para seus alunos tanto presenciais como à distância sendo "[...] composto por um sistema de administração de atividades educacionais voltado à aprendizagem colaborativa, o que possibilita a integração entre estudantes e docentes em cursos online com o objetivo de disponibilizar mecanismos para gerenciar e promover a aprendizagem" (Perez et al., 2012, p. 148).

Instituições utilizam esta plataforma para promover o ensino à distância por meio de comunidades virtuais amplamente colaborativas que possibilitam a aprendizagem baseada em fóruns, atividades, banco de dados, compartilhamento de conteúdos e chats. De acordo com o site oficial do sistema Moodle ${ }^{1}$, também referenciado pelo site do Moodle da Universidade Federal de Santa Catarina (2013) ${ }^{2}$, o sistema procura cobrir três eixos básicos do processo de ensino-aprendizagem:

a) Gerenciamento de conteúdos: organização de conteúdos a serem disponibilizados aos estudantes no contexto de disciplinas/turmas;

b) Interação entre usuários: diferentes ferramentas para interação com e entre estudantes e professores: fórum, bate-papo, mensagem instantânea etc.;

c) Acompanhamento e avaliação: definição, recepção e avaliação de tarefas, questionários e enquetes, atribuição de notas, cálculo de médias etc.

Segundo os desenvolvedores do Moodle, o AVA também é uma ferramenta que possibilita suporte tanto aos professores diante do processo de ensino, como aos alunos nos processos de aprendizagem. Possibilita, igualmente, a integração dos recursos necessários para o gerenciamento de um curso, podendo ser utilizado gratuitamente por estudantes e de múltiplos dispositivos. Apresenta flexibilidade no desenvolvimento de ferramentas, e permite a qualquer pessoa contribuir e participar de um sistema coletivo de educação.

Ainda segundo Perez et al. (2012), no final de 2012, o Moodle era utilizado em cerca de 220 países, disponível em 80 idiomas diferentes e com aproximadamente 6,9 milhões de cursos cadastrados, chegando a 64 milhões de usuários. Dada a amplitude do Moodle, o sistema pode ser utilizado a partir de três formatos diferenciados (Perez et al., 2012, p. 148):

a) Social: com temas discutidos em um fórum publicado na página principal;

b) Semanal: o curso é organizado em semanas, com datas de início e término;

c) Tópicos: cada assunto estudado ou discutido representa um tópico. Não apresenta limite de tempo pré-definido.

Seus principais recursos são: base de dados: que permite download e upload de arquivos como exercícios, livros e materiais didáticos; chat: que serve para discussões em tempo real; fórum: para postagem de comentários e exercícios sobre determinados assuntos; tarefas: para postagem de tarefas com prazos definidos.

\section{A educação à distância e o Moodle no Instituto Federal de Educação, Ciência e Tecnologia de Santa Catarina}

O Instituto Federal de Educação, Ciência e Tecnologia de Santa Catarina (IFSC) é uma instituição pública federal vinculada ao Ministério da Educação (MEC) por meio da Secretaria de Educação Profissional e Tecnológica (SETEC). A Instituição foi inaugurada em Florianópolis em 1909, como Escola de Aprendizes Artífices e, em 2008, se tornou um Instituto Federal de educação básica, profissional e superior distribuído por 22 campi com foco no ensino profissional e tecnológico, contemplando a educação inclusiva e à distância.

A EAD no IFSC teve início desde o ano 2000 no Campus São José com um curso de Manutenção de Ar Condicionado. Desde então, as atividades cresceram e se expandiram para o mais antigo Campus, o IFSC - Campus Florianópolis que, de acordo com o Departamento de Educação a Distância do IFSC, conta com mais de 1850 alunos matriculados e 175 tutores, professores e outros envolvidos no gerenciamento dos cursos, que hoje, estão espalhados em mais de 18 polos diferentes (Campos, Anjos, \& Gontijo, 2013).

As dinâmicas de ensino dos cursos EAD são focadas no Moodle. As aulas ocorrem por videoconferências em encontros presenciais nos polos semanalmente e todas as demais atividades didáticas desenvolvidas acontecem por meio do Moodle. Os tutores gerenciam as disciplinas para postagem de material de apoio, produção e fechamento de atividades, realização de avaliações e controle do desempenho do aluno, bem como controle de seus acessos e postagens. Os professores utilizam o Moodle para compartilhar conteúdos, promover fóruns de discussões, realizar atividades, marcam encontros no chat e monitoram o desempenho do aluno e seus acessos ao ambiente virtual. Além do tutor da disciplina, a estrutura do curso tem uma coordenação, um tutor de Moodle para postar atividades e gerenciar acessos, um tutor de design instrucional que desenvolve leiautes e a arquitetura da informação do sistema e um tutor de monografia, responsável pela postagem e apresentação

\footnotetext{
${ }^{1}$ https://moodle.org

${ }^{2}$ https://moodle.ufsc.br
} 


\section{0}

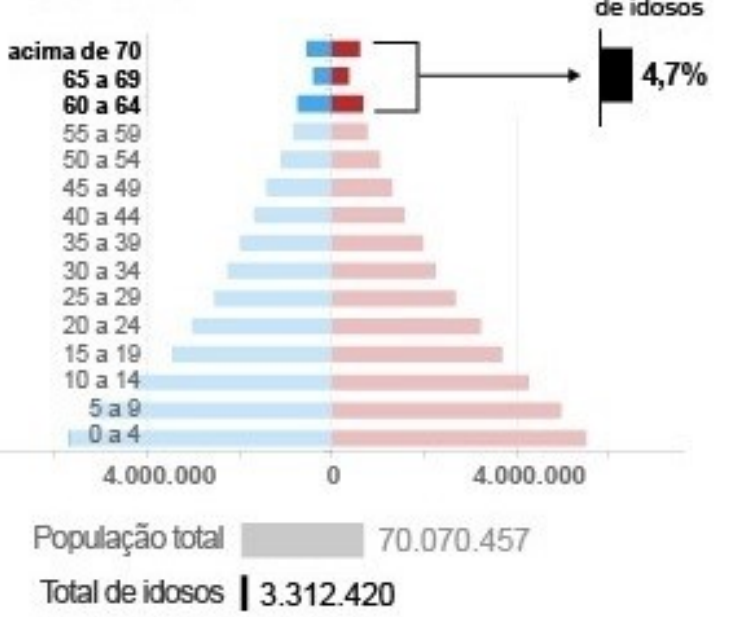

\section{0}

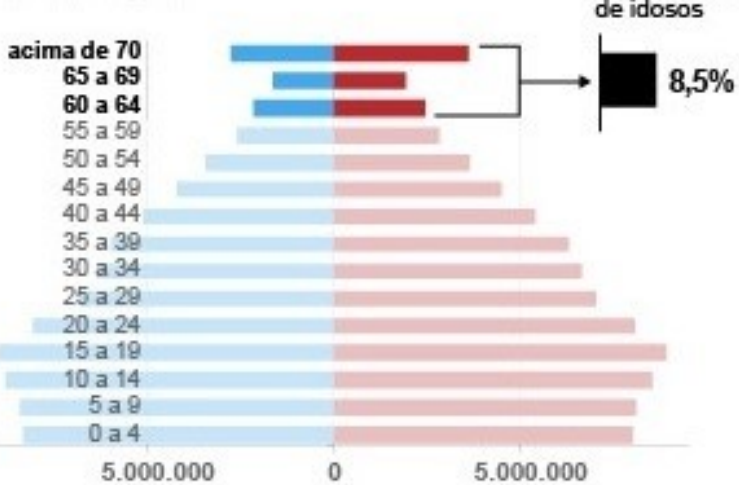

População total

Total de idosos

14.536 .029

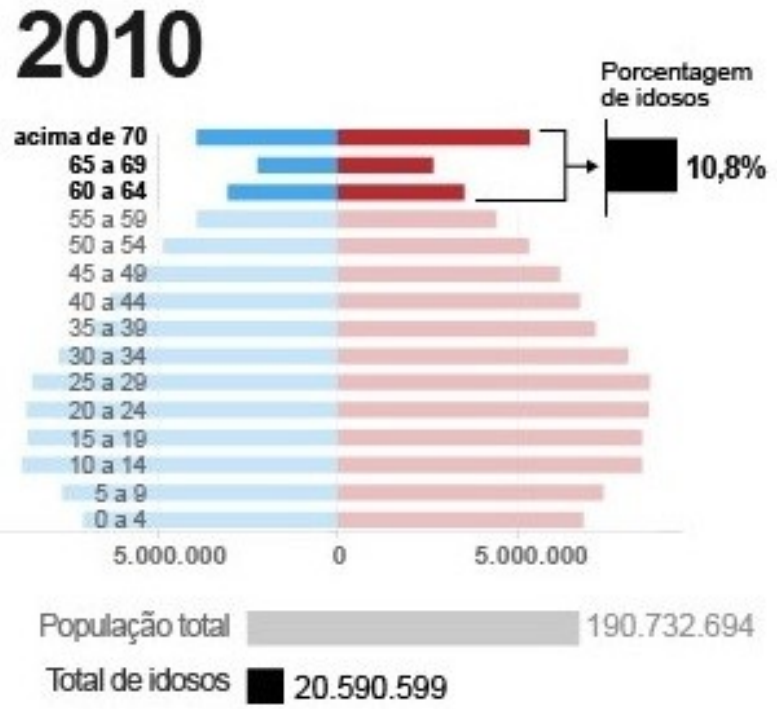

Figura 2. Distribuição da população brasileira por sexo e faixa etária nos Censos de 1960, 2000 e 2010. Fonte: adaptado de Globo Comunicação e Participações S. A. [Globo] (2014).

dos trabalhos finais. Uma descrição detalhada das principais funcionalidades do AVA-Moodel do IFSC e seus responsáveis, encontra-se no apêndice 1.

\section{AS PESSOAS IDOSAS E AS CARACTERÍSTICAS DO ENVELHECIMENTO}

O Censo Demográfico 2010 aponta que o Brasil possui mais 190,7 milhões de habitantes, sendo que a população de idosos é superior a 20,5 milhões de idosos (Instituto Brasileiro de Geografia e Estatística [IBGE], 2010). É possível visualizar na figura 2 a distribuição da população brasileira por sexo e por idade durante os censos de 1960, 2000 e 2010. Nota-se o crescimento da população idosa brasileira ao longo dos anos, o que indica um aumento na expectativa de vida e, consequentemente, a potencial inserção dos idosos no uso de recursos digitais.

Com os avanços da Medicina e uma melhor qualidade de vida, é pertinente considerar que a idade avançada não indica o fim da vida de uma pessoa, mas apenas a intensidade das atividades do dia a dia que diminuem (Ribeiro, 2009).

O processo de envelhecimento provoca alterações físicas e fisiológicas e, ao longo do avanço da idade, é intrínseco, progressivo e irreversível (Ribeiro, 2009). Inevitavelmente, pessoas idosas apresentam algumas características que interferem na cognição e nas práticas motoras. Segundo Aumüller et al. (2009) Souza e Rossini (2011), à medida que as pessoas envelhecem, podem ocorrer alterações como: redução da capacidade 


\begin{tabular}{|c|c|c|c|c|c|}
\hline & $\begin{array}{l}\text { Sistema básico } \\
\text { de orientação }\end{array}$ & $\begin{array}{l}\text { Sistema } \\
\text { auditivo }\end{array}$ & $\begin{array}{l}\text { Sistema } \\
\text { háptico }\end{array}$ & $\begin{array}{c}\text { Sistema } \\
\text { paladar-olfato }\end{array}$ & Sistema visual \\
\hline 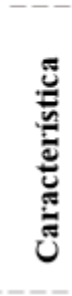 & $\begin{array}{l}\text { Ocorre no labirinto e é } \\
\text { responsável pelo } \\
\text { equilibrio e postura do } \\
\text { corpo estático }\end{array}$ & $\begin{array}{l}\text { Ocorre no ouvido e é } \\
\text { responsável pela } \\
\text { orientação do } \\
\text { individuo a partir dos } \\
\text { sons }\end{array}$ & $\begin{array}{l}\text { Ocorre nas células } \\
\text { presentes na pele, } \\
\text { articulações e } \\
\text { músculos e é } \\
\text { responsável pela } \\
\text { percepção de toque, } \\
\text { textura, temperatura e } \\
\text { movimento. }\end{array}$ & $\begin{array}{l}\text { Ocorre nas células do } \\
\text { nariz e boca e é } \\
\text { responsável pela } \\
\text { compreensão das } \\
\text { composições dos } \\
\text { objetos ingeridos ou } \\
\text { inalados. }\end{array}$ & $\begin{array}{l}\text { Ocorre nos olhos e é } \\
\text { responsável pela } \\
\text { percepção do espaço a } \\
\text { partir da luz, } \\
\text { detectando formas, } \\
\text { profundidades, } \\
\text { distâncias e cores. }\end{array}$ \\
\hline 总 & $\begin{array}{c}\text { Diminuição do } \\
\text { equilibrio, } \\
\text { ocasionando } \\
\text { dificuldade em lidar } \\
\text { com o auto } \\
\text { deslocamento e em } \\
\text { selecionar as } \\
\text { informações } \\
\text { sensoriais. }\end{array}$ & $\begin{array}{l}\text { Diminuição na } \\
\text { discriminação de sons } \\
\text { e percepção da fala. }\end{array}$ & $\begin{array}{c}\text { Diminuição da } \\
\text { sensibilidade tátil na } \\
\text { palma das mãos e nas } \\
\text { solas dos pés. }\end{array}$ & $\begin{array}{l}\text { Diminuição na } \\
\text { sensação gustativa, } \\
\text { perda do interesse pela } \\
\text { comida e diminuição } \\
\text { na percepção de } \\
\text { odores }\end{array}$ & $\begin{array}{c}\text { Diminuição da } \\
\text { acuidade visual, do } \\
\text { campo visual } \\
\text { periférico, da noção de } \\
\text { profundidade, da } \\
\text { discriminação de cores } \\
\text { e da capacidade de } \\
\text { adaptação ao claro e } \\
\text { escuro. }\end{array}$ \\
\hline
\end{tabular}

Figura 3. Alterações nos sistemas sensoriais com o processo de envelhecimento.

Fonte: adaptado de Macedo (2009).

de memória de curto prazo, acuidade visual, audição, mobilidade, locomoção dentre outras. Além disso, se reduz a velocidade de processamento das informações, e a precisão e resposta aos estímulos se torna mais lenta. Algumas alterações que ocorrem nos sistemas sensoriais dos idosos durante o processo de envelhecimento são arroladas na figura 3.

Os idosos, em geral, são mais lentos para processar e recordar informações e aprender coisas novas . Eles mantêm a habilidade de aprendizado, porém o processo leva mais tempo, especialmente quando se trata de algo mais complexo (Anjos, 2012). Logo, é fundamental que, ao se projetarem produtos/sistemas, sejam consideradas essas e outras alterações sofridas por este grupo de usuários.

\section{ERGONOMIA, USABILIDADE E ACESSIBILIDADE NA TERCEIRA IDADE}

Ergonomia é, de acordo com a Associação Internacional de Ergonomia (IEA), uma disciplina científica relacionada ao entendimento das interações entre os seres humanos e outros elementos ou sistemas (Associação Brasileira de Ergonomia [Abergo], 2014). Para esse entendimento é preciso aplicar teorias, princípios, dados e métodos a projetos para garantir o bem estar humano e maximizar o desempenho global do sistema (Associação Brasileira de Ergonomia [Abergo], 2014). Moraes e Mont’Alvão (2003), por sua vez, conceituam a ergonomia como é a ciência que objetiva adaptar o trabalho ao trabalhador e o produto ao usuário.

Partindo da ideia que a ergonomia aborda a interação homem-sistema, ela visa adaptar o sistema às necessidades dos usuários e, por meio da usabilidade, podem-se desenvolver sistemas mais fáceis de aprender, fáceis de usar, fáceis de lembrar, tolerante a erros e agradáveis ao uso (Anjos, 2012). De acordo com a NBR ISO 9241-11 (Associação Brasileira de Normas Técnicas [ABNT], 2002), a usabilidade é a capacidade que um produto tem de oferecer ao seu usuário, em um contexto específico de uso, a realização das tarefas e objetivos específicos com eficácia, eficiência e satisfação; a eficácia é a "acurácia e completude com as quais usuários alcançam objetivos específicos” (Associação Brasileira de Normas Técnicas [ABNT], 2002, p. 3); a eficiência se refere aos "recursos gastos em relação à acurácia e abrangência com as quais usuários atingem os objetivos" (Associação Brasileira de Normas Técnicas [ABNT], 2002, p. 3); e, a satisfação se refere a "ausência do desconforto e presença de atitudes positivas com o uso de um produto" (Associação Brasileira de Normas Técnicas [ABNT], 2002, p. 3).

Cybis et al. (2010) apresentam que a usabilidade é a qualidade que caracteriza o uso dos programas e aplicações. Assim, ela não é uma qualidade intrínseca de um sistema, mas depende de um acordo entre as características de sua interface e as características de seus usuários ao buscarem determinados objetivos em determinadas situações de uso.

Ilda (2005) declara que a usabilidade não depende unicamente das características do produto; depende também do usuário, dos objetivos pretendidos e do ambiente em que o produto é utilizado. De acordo com Cybis et al. (2010), problemas de usabilidade em um software podem ser derivados de qualquer característica observada que pode retardar, prejudicar ou inviabilizar a realização de uma tarefa, aborrecendo ou constrangendo o usuário.

A acessibilidade está ligada aos processos de ergonomia e usabilidade, permitindo que usuários possam utilizar um produto, serviço ou meio físico da melhor forma possível. Segundo a NBR 15250 (Associação Brasileira de 
Normas Técnicas [ABNT], 2005, p. 1) acessibilidade é "possibilidade e condição de alcance para utilização do meio físico, meios de comunicação, produtos e serviços, por pessoa com deficiência”. A mesma norma diz que deficiência é a "perda ou anormalidade de uma estrutura ou função psicológica, fisiológica ou anatômica que gere impossibilidade ou dificuldade para o desempenho de atividade, dentro do padrão considerado normal para o ser humano" (Associação Brasileira de Normas Técnicas [ABNT], 2005, p. 2).

A Iniciativa Acessibilidade Web (WAI) auxilia na promoção da acessibilidade, permitindo que pessoas com deficiência participem igualmente na Web (World Wide Web Consortium, c2013). A WAI disponibiliza recomendações e orientações para auxiliar a criação de conteúdos Web acessíveis visando tanto as pessoas com deficiência quanto para os idosos, tais como as Recomendações de Acessibilidade para o Conteúdo da Web 2.0 (WCAG) (Anjos, 2012).

Usabilidade e acessibilidade estão relacionadas, pois ambas buscam melhorar a utilização das interfaces pelos usuários, com eficiência, a eficácia e a satisfação no uso. Porém, a acessibilidade busca atingir um público mais amplo e genérico, visto que ela é usada para delinear problemas de usabilidade e o que é utilizável por pessoas com deficiências é igualmente usável por quem não as têm (Flor, 2009). Macedo (2009) destaca que a acessibilidade não deve estar associada apenas à necessidade de pessoas com deficiência e sim do público em geral. O conceito complementar de interatividade é tratado por Gosciola (Gosciola, 2003, p. 87), no campo das Ciências da Comunicação e das novas tecnologias como "[...] um recurso de troca ou comunicação de conhecimento, de idéia(sic), de expressão artística, de sentimento”.

Ao se estudar a acessibilidade e a usabilidade no Moodle percebe-se que a interação usuário-sistema se constitui da união entre a comunicação do sistema com o processo de escolha do usuário. O Moodle se apresenta tanto como um sistema roteirizado planejado para traçar caminhos lógicos para o desempenho de funções pré-estabelecidas (sem muitas intervenções do usuário no sistema), como também permite funcionalidades de personalização. Dessa forma o usuário tem suas intervenções guiadas dentro do sistema e determinadas por ele.

Ao se considerar os déficits físicos e cognitivos do público idoso torna-se importante projetar um sistema que considere tais características a fim de propiciar meios para que esses indivíduos consigam executar as suas atividades da melhor forma possível, com eficácia, eficiência e satisfação.

\section{ANÁLISE DO MOODLE DO INSTITUTO FEDERAL DE EDUCAÇÃO, CIÊNCIA E TECNOLO- GIA DE SANTA CATARINA}

Cada etapa metodológica apresentada anteriormente gerou um produto e os resultados seguem abaixo:

a) etapa 1: lista de recomendações de usabilidade e acessibilidade com foco no usuário idoso;

b) etapa 2: a relação das funcionalidades existentes no Moodle com os possíveis problemas de usabilidade e acessibilidade;

c) etapa 3:a relação dos problemas de usabilidade e acessibilidade com o impacto das alterações do envelhecimento; e

d) etapa 4: a lista das recomendações de usabilidade e acessibilidade para o Moodle do IFSC com foco no usuário idoso (Quadro 1).

A relação das funcionalidades existentes no Moodle com os possíveis problemas de usabilidade e acessibilidade pode ser visualizada na Quadro 2.

As sugestões e recomendações de usabilidade e acessibilidade com foco no usuário idoso para o Moodle da IFSC, agrupadas pelas funcionalidades do AVA, podem ser visualizadas a seguir:

- Geral

Característica: Tamanho do texto

Avaliação do Moodle: Não apresenta configuração de tamanho de fontes. Não apresenta a ferramenta "zoom". Recomendação: Muitos idosos necessitam de texto grande ou a possibilidade de configuração para aumento/ diminuição dos textos. Está associada à diminuição da capacidade visual, incluindo textos nos campos de formulário e outros controles.

Característica: Estilo do Texto e Layout.

Avaliação do Moodle: O sistema é configurado em fonte sem serifa, em tamanho razoável, 12pt. Os textos não são muito destacados por cores e formas, exceto em alguns menus específicos. Uso que promove o cansaço devido ao contraste de cores: fonte preta sobre fundo amarelo claro. De maneira geral, os menus não possuem um destaque maior.

Recomendação: Estilo do texto, como fontes, tamanhos e formatos, a justificação do texto, espaçamento entre linhas, comprimento de linha e rolagem horizontal, bem como cores de fundo e contrastes impactam em quão 
fácil ou difícil é para as pessoas lerem.

Característica: Cor e Contraste

Avaliação do Moodle: O problema mais relevante encontrado foi no menu do usuário. O contraste de cores é o mesmo para todas as informações o que causa cansaço na procura da função. Contraste de cores do sistema inadequado, sem grandes destaques para as informações principais e cores cansativas.

Recomendação: A utilização de cores exige que a cor não seja usada como único meio de transmitir informação, indicar uma ação, solicitar uma resposta ou distinguir um elemento visual. Deve-se assegurar também que todas as informações veiculadas com cor estejam também disponíveis sem cor, por exemplo, a partir do contexto ou de anotações. A relação de contraste melhora a apresentação visual de texto e imagens. A maioria dos idosos apresenta alteração na percepção das cores e perda da sensibilidade do contraste.

Característica: Navegação e localização.

Avaliação do Moodle: Apresenta atalhos no menu principal do usuário. A navegação não é intuitiva, necessitando de conhecimento prévio dos caminhos do sistema para executar uma função.

Recomendação: Muitos idosos necessitam de navegação que seja particularmente clara devido à diminuição da capacidade cognitiva. Várias formas de chegar a uma função devem ser apresentadas, inclusive atalhos. Fornecer mecanismos de navegação coerentes e sistematizados - informações de orientação, atalhos, barras de navegação, etc. - para aumentar as probabilidades de uma pessoa encontrar o que procura.

\begin{tabular}{|c|c|}
\hline Característica & Recomendação \\
\hline Tamanho do texto & $\begin{array}{l}\text { Os idosos necessitam de texto grande ou a possibilidade de configuração para } \\
\text { aumento/diminuição dos textos. }\end{array}$ \\
\hline Estilo do Texto e Layout & $\begin{array}{l}\text { Estilo do texto, como fontes, tamanhos e formatos, a justificação do texto, es- } \\
\text { paçamento entre linhas, comprimento de linha e rolagem horizontal, bem como } \\
\text { cores de fundo e contrastes impactam em quão fácil ou difícil é a leitura para os } \\
\text { idosos. }\end{array}$ \\
\hline Cor e Contraste & $\begin{array}{l}\text { A utilização de cores exige que a cor não seja usada como único meio de transmitir } \\
\text { informação, indicar uma ação, solicitar uma resposta ou distinguir um elemento } \\
\text { visual. Deve-se assegurar também que todas as informações veiculadas com } \\
\text { cor estejam também disponíveis sem cor, por exemplo, a partir do contexto ou } \\
\text { de anotações. A relação de contraste melhora a apresentação visual de texto e } \\
\text { imagens. }\end{array}$ \\
\hline Navegação e localização & $\begin{array}{l}\text { Várias formas de chegar a uma função devem ser apresentadas, inclusive atalhos. } \\
\text { Fornecer mecanismos de navegação coerentes e sistematizados - informações de } \\
\text { orientação, atalhos, barras de navegação, etc. - para aumentar as probabilidades } \\
\text { do idoso encontrar o que procura. }\end{array}$ \\
\hline Nomes das funções & $\begin{array}{l}\text { As funções e comandos devem ter nomes fáceis de identificar sem dupla inter- } \\
\text { pretação. }\end{array}$ \\
\hline Feedback & $\begin{array}{l}\text { A interface deve oferecer feedback informativo com respostas visuais e sonoras, } \\
\text { quando possível. }\end{array}$ \\
\hline $\begin{array}{l}\text { Funções e Informações mais } \\
\text { importantes }\end{array}$ & $\begin{array}{l}\text { Informações mais importantes devem ser colocadas no topo das telas e em } \\
\text { destaque. }\end{array}$ \\
\hline Número de telas & $\begin{array}{l}\text { A interface deve apresentar o menor número possível de telas e que a informação } \\
\text { seja mais acessível, possibilitando o menor número de passos e comandos. }\end{array}$ \\
\hline Atalhos & $\begin{array}{l}\text { Os atalhos são necessários para que os idosos possam executar uma função com } \\
\text { mais rapidez e mais confiança. }\end{array}$ \\
\hline Rótulos & $\begin{array}{l}\text { As pessoas idosas necessitam de rótulos e legendas claras para compreender da } \\
\text { melhor forma possível uma função. }\end{array}$ \\
\hline Rolagem da tela & $\begin{array}{l}\text { Existe uma dificuldade para alguns idosos utilizarem a rolagem da tela devido à } \\
\text { diminuição da destreza e cognição. À medida que o usuário vai rolando as telas, } \\
\text { mais informações ele precisa armazenar para que aquilo que ele não está vendo } \\
\text { possa lhe fazer sentido. Quanto menor a tela do monitor, menos informação fica } \\
\text { visível ao usuário, aumentando a sua carga cognitiva. Se não for possível evitar } \\
\text { o uso de rolagem da tela, devem-se colocar indicadores para que o usuário se } \\
\text { situe em relação a todo o conteúdo disponível. }\end{array}$ \\
\hline Redimensionar texto & $\begin{array}{l}\text { É recomendado que os usuários idosos possam redimensionar o texto para me- } \\
\text { lhorar a visibilidade e leitura, incluindo os ícones. }\end{array}$ \\
\hline Tamanho da janela & $\begin{array}{l}\text { O tamanho da janela deve ser apropriado para que o usuário idoso possa ler as } \\
\text { mensagens sem ficar rolando a tela. Além disso, deve permite que o usuário } \\
\text { configure o tamanho desejado da janela. }\end{array}$ \\
\hline
\end{tabular}

Quadro 1. Recomendações de usabilidade e acessibilidade para o Moodle do IFSC com foco no usuário idoso Fonte: os autores (2015). 


\begin{tabular}{|c|c|}
\hline Funcionalidade & Problemas de usabilidade e acessibilidade do Moodle do IFSC \\
\hline Geral & $\begin{array}{l}\text { Não apresenta configuração de tamanho de fontes. Não apresenta a ferramenta } \\
\text { "zoom”. Os textos não são destacados por cores e formas, exceto em alguns } \\
\text { menus específicos. Os menus geralmente não possuem destaque. O contraste } \\
\text { de cores é o mesmo para todas as informações o que causa cansaço na procura } \\
\text { da função. Contraste de cores do sistema inadequado, sem grandes destaques } \\
\text { para as informações principais e cores cansativas. A navegação não é intuitiva, } \\
\text { necessitando de conhecimento prévio dos caminhos do sistema para executar } \\
\text { uma função. Não apresenta feedback efetivo (visual e sonoro) }\end{array}$ \\
\hline Criar e importar conteúdo & $\begin{array}{l}\text { As funções apresentam nomenclaturas simples, porém alguns nomes podem } \\
\text { causar confusão para o usuário idoso. A navegação não é intuitiva, necessitando } \\
\text { de conhecimento prévio dos caminhos do sistema para executar uma função. }\end{array}$ \\
\hline Armazenar recursos & $\begin{array}{l}\text { As informações mais relevantes se encontram no topo, porém alguns links diretos } \\
\text { estão na parte inferior da tela. }\end{array}$ \\
\hline Realizar avaliação & Apresenta várias telas para executar a função. \\
\hline $\begin{array}{l}\text { Adicionar e reproduzir con- } \\
\text { teúdo multimídia }\end{array}$ & $\begin{array}{l}\text { A navegação não é intuitiva, necessitando de conhecimento prévio dos caminhos } \\
\text { do sistema para executar uma função. }\end{array}$ \\
\hline E-mail & Não apresenta alguns rótulos para ícones, dificultando a interpretação da função. \\
\hline Painel de notícias & $\begin{array}{l}\text { A navegação não é intuitiva, necessitando de conhecimento prévio dos caminhos } \\
\text { do sistema para executar uma funça. }\end{array}$ \\
\hline Comunicação assíncrona & $\begin{array}{l}\text { As informações importantes se encontram no topo, porém alguns links diretos } \\
\text { como "mensagens" estão na parte inferior da tela. }\end{array}$ \\
\hline Chat & $\begin{array}{l}\text { Apresenta rolagem na tela, não permite redimensionar texto e o tamanho da } \\
\text { janela de chat é pequena e o tamanho é fixo, ou seja, não permite redimensiona- } \\
\text { mento. }\end{array}$ \\
\hline
\end{tabular}

Quadro 2. Funcionalidades do Moodle do IFSC e os possíveis problemas de usabilidade e acessibilidade encontrados

Fonte: os autores (2015).

\section{- Criação e importação de conteúdo}

Característica: Nomes das funções.

Avaliação do Moodle: Funções com nomenclaturas simples porém alguns nomes podem causar confusão para o usuário idoso. Recomendação: As funções e comandos devem ter nomes fáceis de identificar sem dupla interpretação.

Característica: Feedback.

Avaliação do Moodle: O sistema apresenta feedback visual, alterando os itens clicáveis no momento da ação. Recomendação: A interface deve oferecer feedback informativo com respostas visuais e sonoras, quando possível. Esta recomendação está associada às alterações cognitivas, visuais e auditivas do indivíduo.

\section{- Armazenar recursos}

Característica: Funções e Informações mais importantes.

Avaliação do Moodle: As informações importantes se encontram no topo, porém alguns links diretos como "mensagens" estão na parte inferior da tela.

Recomendação: Informações mais importantes devem ser colocadas no topo das telas e em destaque.

\section{- Realizar avaliação}

Característica: Número de telas.

Avaliação do Moodle: Apresenta um número grande de telas para executar determinadas funções.

Recomendação: A interface deve apresentar o menor número possível de telas e que a informação seja mais acessível, possibilitando o menor número de passos e comandos.

\section{- Criação e importação de conteúdo}

Característica: Nomes das funções.

Avaliação do Moodle: Funções com nomenclaturas simples.

Recomendação: As funções e comandos devem ter nomes fáceis de identificar sem dupla interpretação.

- Adicionar e reproduzir conteúdo multimídia Característica: Feedback.

Avaliação do Moodle: O sistema apresenta feedback visual, alterando os itens clicáveis no momento da ação. 
Recomendação: A interface deve oferecer feedback informativo com respostas visuais e sonoras, quando possível. Esta recomendação está associada às alterações cognitivas, visuais e auditivas do indivíduo.

\section{- E-mail}

Característica: Atalhos.

Avaliação do Moodle: Alguns atalhos presentes.

Recomendação: Os atalhos são necessários para que os idosos possam executar uma função com mais rapidez e mais confiança.

Característica: Rótulos.

Avaliação do Moodle: Não apresenta alguns rótulos para ícones, dificultando a interpretação da função.

Recomendação: As pessoas idosas necessitam de rótulos e legendas, claras para compreender da melhor forma possível uma função.

Característica: Feedback.

Avaliação do Moodle: O sistema apresenta feedback visual, apresentando caixas de mensagens quando alguma ação é executada.

Recomendação: A interface deve oferecer feedback informativo com respostas visuais e sonoras, quando possível. Esta recomendação está associada às alterações cognitivas, visuais e auditivas do indivíduo.

\section{GeralPainel de notícias}

Característica: Funções e Informações mais importantes.

Avaliação do Moodle: As informações importantes se encontram no topo.

Recomendação: Informações mais importantes devem ser colocadas no topo das telas e em destaque.

\section{Comunicação assíncrona}

Característica: Funções e Informações mais importantes.

Avaliação do Moodle: As informações importantes se encontram no topo, porém alguns links diretos como "mensagens" estão na parte inferior da tela.

Recomendação: Informações mais importantes devem ser colocadas no topo das telas e em destaque.

\section{- Chat}

Característica: Rolagem da tela.

Avaliação do Moodle: Apresenta rolagem na tela de chat.

Recomendação: Existe uma dificuldade para alguns idosos utilizarem a rolagem da tela devido à diminuição da destreza e cognição. À medida que o usuário vai rolando as telas, mais informações ele precisa armazenar para que aquilo que ele não está vendo possa lhe fazer sentido. Quanto menor a tela do monitor, menos informação fica visível ao usuário, aumentando a sua carga cognitiva. Se não for possível evitar o uso de rolagem da tela, devem-se colocar indicadores para que o usuário se situe em relação a todo o conteúdo disponível.

Característica: Redimensionar texto.

Avaliação do Moodle: Não permite.

Recomendação: É recomendado que os usuários idosos possam redimensionar o texto para melhorar a visibilidade e leitura, incluindo os ícones.

Característica: Tamanho da janela.

Avaliação do Moodle: $\mathrm{O}$ tamanho da janela de chat é pequena e não permite redimensionamento.

Recomendação: O tamanho da janela deve ser apropriado para que o usuário idoso possa ler as mensagens sem ficar rolando a tela. Além disso, deve permite que o usuário configure o tamanho desejado da janela.

As recomendações de usabilidade e acessibilidade propostas podem ser utilizadas para o projeto de outros ambientes virtuais que possuem as funcionalidades apresentadas, porém pode ser necessário adaptá-las de acordo com o ambiente. 


\section{CONSIDERAÇÕES FINAIS}

Este estudo parte da problemática de identificar os possíveis desafios que o idoso encontra ao interagir com a interface do ambiente virtual de aprendizagem e busca sistematizar quais são os parâmetros que podem ser utilizados para adequar o sistema, a fim de minimizar ou extinguir os problemas enfrentados pelos idosos na interação com esse tipo de interface. A partir disso, foram realizadas avaliações ergonômicas de acessibilidade e usabilidade com foco nas dificuldades e limitações que o púbico idoso pode encontrar durante a interação com o sistema, as quais foram essenciais para identificar algumas fragilidades no AVA e propor certos ajustes visando à adequação do AVA e, posteriormente, proporcionar ao público idoso uma experiência mais eficiente comparada com a anterior. Assim, conseguiu-se atingir o objetivo principal desta pesquisa caracterizado como a verificação da ergonomia do sistema Moodle do IFSC por meio de ferramentas para avaliar a usabilidade e acessibilidade do sistema em relação ao público idoso. Ao atingir o objetivo central da pesquisa por meio dos estudos apresentados, tornou-se possível sistematizar os dados levantados para adequação do AVA e, assim que colocados em prática, poderão fomentar a interação e o processo comunicacional entre sistema e estudante idoso. Este fato tem consequências não apenas numa nova proposta (acredita-se que melhorada) do AVA como também influencia diretamente na motivação e concretização dos estudos por parte dos alunos da terceira idade. Como visto, durante o processo de envelhecimento ocorrem alterações biológicas no ser humano, resultando em déficits físicos, cognitivos e visuais, por exemplo. Pode-se concluir que as dificuldades encontradas pelos idosos, mesmo que leves, podem gerar consequências durante a interação com produtos e sistemas, neste caso, com o ambiente de ensino à distância.

As recomendações servem de apoio para a construção de AVAs, voltado ao publico idoso, a partir de funcionalidades presentes e características das interfaces. O estudo possibilita recomendações para a construção de AVAs mais eficientes, eficazes e satisfatórios para os idosos, capazes de contornar alguns problemas físicos e cognitivos decorrentes da idade.

Comandos simples, layouts, arquitetura de informação e a apresentação das informações, clareza nos ícones e rótulos impactam na dificuldade ou facilidade na leitura e compreensão da interface, que tem por objetivo prover uma boa compreensão, em conformidade com as expectativas do usuário, tolerante ao erro, adequado ao aprendizado, navegação intuitiva.

O Moodle do IFSC, utilizado como objeto para efetivação do estudo, apresenta algumas características que podem influenciar negativamente o uso pelo público idoso, como detectado na avaliação heurística. Verificou-se excesso de informações na tela principal, confusão dos ícones por meio da não diferenciação dos mesmos, utilização de cores e contrastes inadequados para separar e destacar informações, número de telas excessivo para executar determinadas tarefas, layout inadequado que necessita de barra de rolagem para visualização dos itens na tela, entre outros aspectos. Por fim, o estudo vislumbra a melhoria do sistema e, principalmente, a necessidade de se pensar no público idoso como utilizador destes sistemas. É possível realizar pequenos ajustes que podem promover a inclusão digital e satisfatória destes usuários que procuram cada vez mais cursos e atividades por meio da tecnologia digital. 


\section{REFERÊNCIAS}

Anjos, T. P. (2012). Descomplicando o uso do telefone celular pelo idoso: desenvolvimento de interface de celular com base nos princípios de usabilidade e acessibilidade (Mestrado em Engenharia de Sistemas, Universidade Federal de Santa Catarina, Florianópolis). Recuperado de http://repositorio.ufsc.br/ xmlui/handle/123456789/100596

Anjos, T. P., Campos, J. V., Gontijo, L. A., \& Viera, M. L. H. (2014). Usabilidade e acessibilidade no moodle: recomendações para o uso do ambiente virtual de ensino e aprendizagem pelo público idoso. Human Factors Design, 3(5), 2342. Recuperado em 17 ago. 2014, de http://www.periodicos .udesc.br/index.php/hfd/article/view/5604/4154

Associação Brasileira de Ergonomia [Abergo]. (2014). O que é ergonomia. Recuperado em 10 nov. 2014, de http:// www.abergo.org.br/internas.php?pg=o_que_e_ergonomia

Associação Brasileira de Normas Técnicas [ABNT]. (2002). NBR ISO 9241-11: Requisitos ergonômicos para trabalho de escritórios com computadores parte 11- orientações sobre usabilidade. Rio de Janeiro: ABNT.

Associação Brasileira de Normas Técnicas [ABNT]. (2005). NBR 15250:2005: Acessibilidade em caixa auto-atendimento bancário. Rio de Janeiro: ABNT.

Aumüller, G., Aust, G., \& Wurzinger, L. (2009). Anatomia. Rio de Janeiro: Guanabara Koogan.

Bastein, C., \& Scapin, D. (1993). Ergonomic criteria for the evaluation of human-computer interfaces. Recuperado em 2 fev. 2015, de http://www.inria.fr

Campos, V. J., Anjos, T. P., \& Gontijo, L. A. (2013). Análise do ambiente virtual de ensino aprendizado do IFSC no contexto da educação à distância. In Anais do Congresso Internacional de Conhecimento e Inovação (p. 619-637). Porto Alegre: PUCRS.

Cybis, W., Betiol, A. H., \& Faust, R. (2010). Ergonomia e usabilidade: conhecimentos métodos e aplicações (2a. ed.). São Paulo: Novatec.

Ferreira, A. M. J. F. C., Vechiato, F. L., \& Vidotti, S. A. B. G. (2008). Arquitetura da informação de web sites: um enfoque à universidade aberta à terceira idade (UNATI). Revista de Iniciação Científica da FFC, 8(1), 114-129. Recuperado em 16 ago. 2015, de http://www2.marilia.unesp.br/revistas/index .php/ric/article/view/184/169

Flor, C. S. (2009). Diagnóstico da acessibilidade dos principais museus virtuais disponíveis da internet (Mestrado em Engenharia e Gestão do Conhecimento, Universidade Federal de Santa Catarina, Florianópolis). Recuperado de http://repositorio.ufsc.br/xmlui/handle/123456789/92907

Globo Comunicação e Participações S. A. [Globo]. (2014). Em 50 anos, percentual de idosos mais que dobra no Brasil. Recuperado em 10 nov. 2014, de http://g1.globo.com/brasil/noticia/2012/04/em-50-anos -percentual-de-idosos-mais-que-dobra-no-brasil.html

Gosciola, V. (2003). Roteiro para novas mídias. São Paulo: Senac.

Hack, J. R. (2011). Introdução à educação à distância. Santa Catarina: UFSC.

Ilda, I. (2005). Ergonomia: Projeto e produção. São Paulo: Edgard Blücher.

Instituto Brasileiro de Geografia e Estatística [IBGE]. (1960). Censo demográfico de 1960: Brasil. Rio de Janeiro: IBGE. Recuperado em 16 ago. 2015, de http://biblioteca.ibge.gov.br/visualizacao/monografias/ GEBIS\%20-\%20RJ/CD1960/CD_1960_Brasil.pdf

Instituto Brasileiro de Geografia e Estatística [IBGE]. (2000). Perfil dos idosos responsáveis pelos domicílios no Brasil 2000. Rio de Janeiro: IBGE. Recuperado em 16 ago. 2015, de http://www.ibge.gov.br/home/estatistica/ populacao/perfilidoso/tabela1_2.shtm

Instituto Brasileiro de Geografia e Estatística [IBGE]. (2010). Sinopse do censo demográfico 2010. Recuperado em 16 ago. 2015, de http://www.censo2010.ibge.gov.br/sinopse/index .php

Macedo, M. K. B. (2009). Recomendações de acessibilidade e usabilidade para ambientes virtuais de aprendizagem voltados para o usuário idoso (Mestrado em Engenharia e Gestão do Conhecimento, Universidade Federal de Santa Catarina, Florianópolis). Recuperado de http://repositorio.ufsc.br/xmlui/ handle/123456789/93284

Moraes, A., \& Mont'Alvão, C. (2003). Ergonomia: Conceitos e aplicações. Rio de Janeiro: Iuser.

Nielsen, J. (1994). Usability engineering. San Francisco, CA, USA: Morgan Kaufman.

Perez, G., Zilber, M. A., Cesar, A. M. R. V. C., Lex, S., \& Medeiros Júnior, A. (2012). Tecnologia de informação para apoio ao ensino superior: o uso da ferramenta moodle por professores de ciências contábeis. Revista de Contabilidade e Negociações, 6(16), 143-164. Recuperado em 13 nov. 2014, de http://www.rco.usp.br/index.php/rco/article/view/520/264

Pottes, A., \& Spinillo, C. G. (2011). Considerações sobre a visualização de sequências pictóricas de procedimentos animadas em dispositivos de interação móvel. In Anais do Congresso Internacional de Design da Informação. Florianópolis: SBDI; UFSC.

Preece, J. (2002). Design de interação: Além da interação homem-computador. Porto Alegre: Bookman.

Ribeiro, T. (2009). Estudo do equilíbrio estático e dinâmico em indivíduos idosos (Mestrado em Ciência do Desporto, Universidade do Porto, Porto, Portugal). Recuperado de http://sigarra.up.pt/fadeup/pt/publs_pesquisa.show_publ file?pct_gdoc_id=1834

Sales, M. B. (2007). Modelo multiplicador utilizando a aprendizagem por pares focado no idoso (Mestrado em Engenharia e Gestão do Conhecimento, Universidade Federal de Santa Catarina, Florianópolis). Recuperado de http://repositorio .ufsc.br/xmlui/handle/123456789/90095

Schneiderman, B. (1998). Designing the user interface: strategies for effective human computer interaction. Reading, MA, USA: Addison Wesley.

Souza, V. C., \& Rossini, J. C. (2011). Os efeitos da idade na seleção de carga perceptual. Psicologia: teoria e pesquisa, 27(2), 131-138. Recuperado em 16 ago. 2015, de http:// dx.doi.org/10.1590/S0102-37722011000200009

World Wide Web Consortium. (c2013). Accessibility. Recuperado em 30 jul. 2013, de http://www.w3.org/standards/ webdesign/accessibility

Zanchett, P. S. (2006). Sistema de hipermídia adaptativa como suporte à orientação de usuários idosos (Mestrado em Engenharia e Gestão do Conhecimento, Universidade Federal de Santa Catarina, Florianópolis). Recuperado de http:// repositorio.ufsc.br/xmlui/handle/123456789/88700 
Campos, J. V., Anjos, T. P., Gontijo, L. A. \& Vieira, M. L. H. (2015). A usabilidade e acessibilidade de um ambiente virtual de aprendizagem com foco no usuário idoso: uma verificação ergonômica do Moodle. AtoZ: novas práticas em informação e conhecimento, 4(1), 10 23. Recuperado de: http://dx.doi.org/10.5380/atoz.v4i1 .41713 


\section{APÊNDICE 1}

\begin{tabular}{|c|c|c|}
\hline Funcionalidade & Agente & Descrição \\
\hline Criar e importar conteúdos & Professor/tutor & $\begin{array}{l}\text { Permite importar e exportar conteúdos de um } \\
\text { curso. }\end{array}$ \\
\hline Armazenar recursos & Professor/tutor & $\begin{array}{l}\text { Permite a criação de repositórios de conteúdo por } \\
\text { meio do upload de arquivos no ambiente. }\end{array}$ \\
\hline Adicionar descrição & Professor/tutor & $\begin{array}{l}\text { Permite criar uma descrição e um nome para cada } \\
\text { recurso. }\end{array}$ \\
\hline $\begin{array}{l}\text { Armazenar e visualizar todos } \\
\text { os dados do aprendiz }\end{array}$ & Professor/tutor & $\begin{array}{l}\text { Permite a visualização do perfil do aluno assim } \\
\text { como as disciplinas que estes estão cursando, ativi- } \\
\text { dades desempenhadas e frequência de acessos. }\end{array}$ \\
\hline $\begin{array}{l}\text { Adicionar e remover apren- } \\
\text { dizes }\end{array}$ & Professor/tutor & $\begin{array}{l}\text { Permite adicionar ou remover alunos de uma deter- } \\
\text { minada disciplina/curso oferecido. }\end{array}$ \\
\hline $\begin{array}{l}\text { Monitorar atividades de } \\
\text { aprendizado }\end{array}$ & Professor/tutor & $\begin{array}{l}\text { Permite o monitoramento do aluno no sentido de } \\
\text { diagnosticar a qualidade da aprendizagem. }\end{array}$ \\
\hline Estruturação de Cursos & Professor/tutor & $\begin{array}{l}\text { Permite criar as disciplinas e estruturá-las sob de- } \\
\text { manda. }\end{array}$ \\
\hline Adição de recursos & Professor/tutor & Permite adicionar materiais, links e outras mídias. \\
\hline Realizar avaliação & Professor/tutor & $\begin{array}{l}\text { Permite criar a avaliação definido pesos para cada } \\
\text { umas das atividades, bem como divulgar seus resul- } \\
\text { tados individualmente. }\end{array}$ \\
\hline $\begin{array}{l}\text { Criação e importação de con- } \\
\text { teúdo }\end{array}$ & Professor/tutor e Aluno & $\begin{array}{l}\text { Permite a importação e exportação das aulas e ou- } \\
\text { tros conteúdos. }\end{array}$ \\
\hline $\begin{array}{l}\text { Adicionar e reproduzir con- } \\
\text { teúdo multimídia }\end{array}$ & Professor/tutor e Aluno & $\begin{array}{l}\text { Permite a reprodução de arquivos multimídia. Em } \\
\text { alguns AVAs, essa funcionalidade depende dos re- } \\
\text { cursos oferecidos pelo navegador e seus plug-ins. }\end{array}$ \\
\hline E-mail & Professor/tutor e Aluno & Permite o envio de e-mails. \\
\hline Painel de notícias & Professor/tutor e Aluno & $\begin{array}{l}\text { Permite publicar notícias e listar essas notícias em } \\
\text { algumas áreas do ambiente. }\end{array}$ \\
\hline Troca de arquivos & Professor/tutor e Aluno & $\begin{array}{l}\text { Permite a troca de arquivos entre os usuários do } \\
\text { ambiente. }\end{array}$ \\
\hline Discussão assíncrona & Professor/tutor e Aluno & $\begin{array}{l}\text { Permite a comunicação dos usuários por meio de } \\
\text { fórum e mensagens personalizadas. }\end{array}$ \\
\hline Chat & Professor/tutor e Aluno & $\begin{array}{l}\text { Permite a comunicação por meio de troca instan- } \\
\text { tânea de mensagens entre os usuários. }\end{array}$ \\
\hline Videoconferência & Professor/tutor e Aluno & $\begin{array}{l}\text { Permite a comunicação instantânea por meio vídeo } \\
\text { entre os usuários. }\end{array}$ \\
\hline
\end{tabular}

Quadro 3. Principais funcionalidades do AVA-Moodle do IFSC e seus responsáveis Fonte: os autores (2015). 